\title{
Kinetic Hydration Heat Modeling for High-Performance Concrete Containing Limestone Powder
}

\author{
Xiao-Yong Wang \\ College of Engineering, Department of Architectural Engineering, Kangwon National University, \\ Chuncheon-si 200701, Republic of Korea \\ Correspondence should be addressed to Xiao-Yong Wang; wxbrave@kangwon.ac.kr
}

Received 15 June 2017; Accepted 1 August 2017; Published 5 September 2017

Academic Editor: Doo-Yeol Yoo

Copyright ( 2017 Xiao-Yong Wang. This is an open access article distributed under the Creative Commons Attribution License, which permits unrestricted use, distribution, and reproduction in any medium, provided the original work is properly cited.

\begin{abstract}
Limestone powder is increasingly used in producing high-performance concrete in the modern concrete industry. Limestone powder blended concrete has many advantages, such as increasing the early-age strength, reducing the setting time, improving the workability, and reducing the heat of hydration. This study presents a kinetic model for modeling the hydration heat of limestone blended concrete. First, an improved hydration model is proposed which considers the dilution effect and nucleation effect due to limestone powder addition. A degree of hydration is calculated using this improved hydration model. Second, hydration heat is calculated using the degree of hydration. The effects of water to binder ratio and limestone replacement ratio on hydration heat are clarified. Third, the temperature history and temperature distribution of hardening limestone blended concrete are calculated by combining hydration model with finite element method. The analysis results generally agree with experimental results of highperformance concrete with various mixing proportions.
\end{abstract}

\section{Introduction}

The use of limestone powder blended cement is a common practice in the modern concrete industry. The benefits from technical, economic, and ecological aspects can be achieved by using limestone blended concrete [1]. Technical benefits mainly refer to limestone powder which can increase the early-age performance of concrete. Economic benefits mean obtaining cement with a compressive strength similar to control concrete at low production costs. The ecological aspects are the reduction of greenhouse gas emission by using limestone.

Many studies in experimental or theoretical aspects have been done about early-age properties and durability of limestone blended concrete. Bonavetti et al. [2] found that the addition of limestone can increase the early-age strength of concrete. However, the late-age strength is impaired due to the dilution effect of limestone addition. Mohammadi and South [3] reported that limestone addition can reduce the bleeding of fresh concrete and increase the viscosity and cohesiveness of fresh concrete. Mohammadi and South [4] also reported that the concrete with various limestone contents up to $12 \%$ has a similar drying shrinkage and sulfate expansion resistance with control concrete. Chen and Kwan [5] measured heat generation of concrete with different limestone stone replacement ratios and binder contents. They found that the addition of limestone can significantly reduce the heat generation of concrete. Palm et al. [6] found that high-level limestone addition can increase the carbonation depth and chloride migration coefficient of concrete. Based on life cycle assessment, Palm et al. [6] also found highlevel limestone additions can reduce the $\mathrm{CO}_{2}$ emission about $25 \%$ in comparison with average cement with the same performance.

Compared with abundant experimental studies, the theoretical models for limestone blended concrete are relatively limited. Lothenbach et al. [7] proposed a thermodynamic model for limestone blended concrete. The formation of monocarboaluminate and bulk compositions of hydrating cement is calculated by thermodynamic models. Bentz [8] proposed a hydration model which analyzed the dilution effect, nucleation effect, and chemical effect of limestone 
addition. Similarly, Mohamed et al. [9] also proposed a model to evaluate reaction degree of hydration for concrete with different limestone additions. However, Lothenbach et al. [7], Bentz [8], and Mohamed et al.'s [9] studies mainly focus on the degree of hydration in cement-limestone blends. The hydration heat is scarcely simulated in their studies. Poppe and Schutter [10] and Ye et al. [11] proposed models to analyze heat evolution of limestone blended selfcompacting concrete. But their study mainly focuses on the isothermal condition or adiabatic temperature rise. For concrete structures in construction sites, the heat release from hydration and heat transfer to ambient environments occurs simultaneously. Poppe and Schutter [10] and Ye et al's [11] studies do not consider semiadiabatic temperature rise in real construction sites.

To overcome the shortcomings in current models [711], we proposed an integrated numerical procedure to analyze the temperature history and temperature distribution of hardening limestone blended concrete. The hydration model is combined with finite element method. The heat of hydration is calculated from the degree of hydration. The reduction of hydration heat due to limestone additions is clarified through analysis.

\section{Hydration Heat Model of Limestone Powder Blended Concrete}

2.1. Hydration Model of Portland Cement. Wang and Lee [12] proposed a kinetic hydration model for Portland cement which takes into account the effects of a water to binder ratio $(W / B)$, compound compositions of cement, fineness of cement, and capillary water contents on the hydration of cement. The kinetic hydration model analyzes the involved kinetic processes of cement hydration, such as initial dormant process, phase boundary reaction-controlled process, and diffusion-controlled process. The kinetic hydration model is valid for concrete with various types of Portland cement, various mixing proportions, and various curing temperatures. The equation for the kinetic hydration model is shown as follows:

$$
\begin{aligned}
\frac{d \alpha}{d t} & =\frac{3 \rho_{w} C_{w-\text { free }}\left(S_{w} / S_{0}\right)}{r_{0} \rho_{c}\left(v+w_{g}\right)} \\
& \cdot \frac{1}{\left(1 / k_{d}-r_{0} / D_{e}\right)+\left(1 / k_{r}\right)(1-\alpha)^{-2 / 3}+\left(r_{0} / D_{e}\right)(1-\alpha)^{-1 / 3}}
\end{aligned}
$$

In (1), $\alpha$ is hydration degree of cement, $k_{d}$ is the hydration rate coefficient in the initial dormant period, $k_{r}$ is the hydration rate coefficient of phase boundary reaction-controlled process, $D_{e}$ is the hydration rate coefficient in the diffusioncontrolled stage, $C_{w \text {-free }}$ denotes the amount of capillary water at the exterior of hydration products, $S_{w}$ denotes the effective contacting surface area between the cement particles and capillary water, and $S_{0}$ denotes the total surface area if hydration products develop unconstrained [12]. Equation (1) also considers chemical and physical aspects of cement hydration. In (1), $v$ is the mass of chemically bound water for one-gram hydrated cement $(=0.25), w_{g}$ is the mass of physically bound water for one-gram hydrated cement $(=0.15), \rho_{w}$ denotes the density of water, $\rho_{c}$ denotes the density of the cement, $r_{0}$ denotes the radius of unhydrated cement particles.

The determinations of reaction coefficients $k_{d}, D_{e}$, and capillary water content $C_{w \text {-free }}$ are shown in (2)-(4), respectively.

$$
\begin{aligned}
k_{d} & =\frac{B}{\alpha^{1.5}}+C \alpha^{3}, \\
D_{e} & =D_{e 0} \ln \left(\frac{1}{\alpha}\right), \\
C_{w \text {-free }} & =\left(\frac{W_{0}-0.4 * \alpha * C_{0}}{W_{0}}\right)^{r} .
\end{aligned}
$$

Equation (2) can be used to determine reaction coefficient $k_{d}$. In (2), $B$ is the rate of the initial impermeable layer formation, and $C$ is the rate of the initial impermeable layer decay.

Equation (3) can be used to determine reaction coefficient $D_{e}$. In (3), $D_{e 0}$ is the initial diffusion coefficient, and $D_{e}$ decreases as cement hydration proceeds.

Equation (4) can be used to determine capillary water content $C_{w \text {-free }}$ In (4), $C_{0}$ is the cement content in mixing proportion, $W_{0}$ is the water content in the mix proportion, and $r\left(r=2.6-4\left(W_{0} / C_{0}\right)\right)$ is an empirical parameter that considers the accessibility of water into an inner anhydrous part through an outer hard shell of cement particles. For highstrength concrete with low $W / C$ ratio at late ages, $C_{w \text {-free }}$ has a significant influence on the rate of hydration.

The influences of temperature on reaction coefficients can be described by using Arrhenius's law [12] as follows:

$$
\begin{aligned}
B & =B_{20} * \exp \left(-\beta_{1}\left(\frac{1}{T}-\frac{1}{293}\right)\right), \\
C & =C_{20} * \exp \left(-\beta_{2}\left(\frac{1}{T}-\frac{1}{293}\right)\right), \\
k_{r} & =k_{r 20} * \exp \left(-\frac{E}{R}\left(\frac{1}{T}-\frac{1}{293}\right)\right), \\
D_{e 0} & =D_{e 20} * \exp \left(-\beta_{3}\left(\frac{1}{T}-\frac{1}{293}\right)\right),
\end{aligned}
$$

where $\beta_{1}, \beta_{2}, E / R$, and $\beta_{3}$ denote the activation energies of $B, C, k_{r}$, and $D_{e 0}$, respectively. $B_{20}, C_{20}, k_{r 20}$, and $D_{e 20}$ denote the values of reaction coefficients $B, C, k_{r}$, and $D_{e 0}$ at $293 \mathrm{~K}$, respectively.

Based on the degree of hydration of concrete with various types of Portland cement and various curing temperatures, Wang [13] proposed that the reaction coefficients of hydration model, such as $B_{20}, C_{20}, k_{r 20}$, and $D_{e 20}$, can be determined from compound compositions of cement. The temperature 
sensitivity coefficients can be approximately regarded as constants for different types of cement [13]. These relationships are shown as follows:

$$
\begin{aligned}
B_{20} & =6 * 10^{-12}\left(C_{3} S \%+C_{3} A \%\right)+4 * 10^{-10}, \\
C_{20} & =0.0003 C_{3} S \%+0.0186, \\
k_{r 20} & =8 * 10^{-8} C_{3} S \%+1 * 10^{-6}, \\
D_{e 20} & =-8 * 10^{-12} C_{2} S \%+7 * 10^{-10}, \\
\beta_{1} & =1000, \\
\beta_{2} & =1000, \\
\frac{E}{R} & =5400, \\
\beta_{3} & =7500 .
\end{aligned}
$$

Summarily, the kinetic hydration model is composed of four rate determining coefficients, that is, the rate of formation of the initial impermeable layer $(B)$, the rate of destruction of initial impermeable layer $(C)$, the rate of phase boundary reaction-controlled process $\left(k_{r}\right)$, and the rate of diffusion-controlled process $\left(D_{e}\right)$. By using compound compositions of cement, the reaction coefficients of kinetic hydration model can be determined. Furthermore, the degree of hydration can be calculated by using (1). The proposed hydration model is valid for Portland cement concrete with various materials properties and curing conditions.

2.2. Effect of Limestone Addition on Cement Hydration. Wang [13] reported that the addition of limestone presents dilution effect, nucleation effect, and chemical effect on cement hydration. Dilution effect is when cement is partially replaced by limestone, the content of cement is reduced and water to cement ratio increases correspondingly. Nucleation effect is that limestone can serve as nucleation sites of hydrating cement particles. Hydration of cement can accelerate due to nucleation effect. Chemical effect is the formation of monocarboaluminate due to limestone reaction in preference to a monosulfoaluminate.

On the other hand, because the reactivity of limestone is very weak compared with other supplementary cementitious materials, limestone can be approximately regarded as chemical inert filler $[1,11]$. Hence in this study, the chemical effect of limestone is not considered.

The dilution effect of limestone powder can be considered by using (4). Wang [13] and Kishi and Saruul [14] proposed that the nucleation effect of limestone relates to the ratio of surface area of cement particles to that of limestone powder. The nucleation effect of limestone powder is significant in phase boundary reaction-controlled process and diffusioncontrolled process. The nucleation effect of limestone powder can be considered as follows:

$$
\begin{aligned}
L_{r} & =\frac{L S_{0} * S_{L S}}{C_{0} * S_{C}}, \\
k_{r L S} & =k_{r}\left(1+A_{1} L_{r}\right), \\
D_{e L S} & =D_{e}\left(1+A_{2} L_{r}\right) .
\end{aligned}
$$

In (7), $L_{r}$ is the limestone nucleation effect indicator, $L S_{0}$ is the mass of limestone in concrete mixing proportions, and $S_{L S}$ is the Blaine surface area of limestone powder.

In (8), $k_{r L S}$ is the updated phase boundary reaction coefficient, and $A_{1}$ is enhanced coefficients of $k_{r}$. In (9), $D_{e L S}$ is the updated diffusion coefficient $D_{e}$, and $A_{2}$ is enhanced coefficients of $D_{e}$. Based on analysis shown later (Section 3.1), the values of $A_{1}$ and $A_{2}$ are set as 0.6 .

Summarily, for a cement-limestone blend, the dilution effect is considered through capillary water concentration. The nucleation effect is considered by nucleation effect indicator which considers binder proportions and surface area of binders. Furthermore, by using updated reaction coefficients, the reaction degree of cement in cement-limestone blends can be determined.

2.3. Temperature History Model of Hardening Concrete. Hydrate heat of hydrating concrete is dependent on both cement content and degree of hydration. The relation heat from hydration of concrete can be determined as follows [1517]:

$$
\frac{d Q}{d t}=C_{0} H_{e} \frac{d \alpha}{d t}
$$

where $Q$ is hydration heat and $H_{e}$ is released hydration heat from a unit mass of cement. $H_{e}$ can be determined by using compound compositions and hydration heat of individual components of cement [15-17].

For hardening concrete, the temperature distribution is in a dynamic heat balance between the hydration heat generation inside the concrete and heat loss to the ambient. The heat generation comes from hydration reactions of the cement. The temperature distribution of hardening concrete is determined as follows [18]:

$$
C_{\mathrm{hc}} \frac{\partial T}{\partial t}=\operatorname{div}(k \nabla T)+\frac{d Q}{d t},
$$

where $C_{\mathrm{hc}}$ is the heat capacity of hydrating concrete and can be calculated as the sum of the individual components of concrete, $k$ is the thermal conductivity of concrete, $T$ is the concrete temperature, $t$ is time, and $d Q / d t$ can be calculated based on the degrees of hydration of the cement (10).

For hardening concrete in construction sites, the boundary condition can be described as follows:

$$
k \nabla T=\beta\left(T_{s}-T_{a}\right),
$$

where $\beta$ is the coefficient of heat convection between concrete surface and ambient; $T_{s}$ is the temperature on the concrete surface; and $T_{a}$ is ambient temperature.

Equation (11) is numerically solved by using finite element method. Three-dimensional (3D) eight-node isoparametric element is used to mesh the geometry model of hardening concrete. The iteration scheme of (11) is shown as follows [1517]:

$$
\begin{aligned}
& \left(\frac{1}{\Delta t}[C]+\theta[B]\right)\{T\}_{n+1} \\
& \quad=\left(\frac{1}{\Delta t}[C]-(1-\theta)[B]\right)\{T\}_{n}+\{P\}_{n},
\end{aligned}
$$


TABLE 1: Mixing proportions of paste for isothermal heat evolution.

\begin{tabular}{lcccccc}
\hline & $\begin{array}{c}\text { Water } \\
(\mathrm{g})\end{array}$ & $\begin{array}{c}\text { Cement } \\
(\mathrm{g})\end{array}$ & $\begin{array}{c}\text { Limestone } \\
(\mathrm{g})\end{array}$ & $\begin{array}{c}\text { Blaine of limestone } \\
\left(\mathrm{cm}^{2} / \mathrm{g}\right)\end{array}$ & Limestone/(cement + limestone) & Water/cement \\
\hline M100 & 5 & 10 & 0 & - & 0 & 0.5 \\
M90L10-35 & 5 & 10 & 1.11 & 3500 & 0.1 & 0.3 \\
M70L30-35 & 5 & 10 & 4.29 & 3500 & 0.3 & 0.5 \\
M70L30-89 & 5 & 10 & 4.29 & 8900 & 0.5 \\
\hline
\end{tabular}

where $[C]$ is the global mass matrix, $[B]$ is global stiffness matrix, $\{P\}$ is the global vector of temperature, and $\theta$ is integration parameter. The global stiffness matrix $[B]$, global mass matrix $[C]$, and global temperature vector $\{P\}$ can be obtained by assembling of element mass matrix, element stiffness matrix, and element temperature vector, respectively. Generally, to guarantee the stability of the numerical integration in a time domain, the value of integration parameter $\theta$ should be higher than 0.5 . In this paper, according to the Galerkin method, the value of the parameter $\theta$ is used as $2 / 3$ [12].

2.4. Summary of the Proposed Numerical Procedure. The numerical procedure consists of a kinetic hydration model and a finite element model. The kinetic hydration model considers the dilution effect and nucleation effect from limestone additions. The heat of hydration of hydrating concrete is calculated by using the degree of hydration and cement content. The calculation results of the heat of hydration are used as a source term in finite element model. By using Galerkin method, the parabolic partial differential equation about temperature distribution of hardening concrete is solved. Temperature history of semiadiabatic temperature rise is calculated considering both concrete materials properties and ambient conditions. The proposed numerical procedure is valuable for thermal cracking analysis of hardening concrete and construction plan design and materials design of concrete structures.

\section{Verification of Proposed Model}

3.1. Heat of Hydration. Experimental results about isothermal heat evolution shown in [14] are used to verify the proposed limestone blended hydration model. Kishi and Saruul [14] measured isothermal hydration heat of limestone blended cement paste. The mixing proportions of paste specimens are shown in Table 1. In Kishi and Saruul's study [14], to demonstrate the nucleation effect of limestone, the water to cement is the same for all specimens. Limestone is added as an additional binder, not replacing partial cement, which is different from the general applications of limestone. The limestone ranges within $10 \%$ and $30 \%$ of total binder, and the Blaine surface area of limestone ranges from $3500 \mathrm{~cm}^{2} / \mathrm{g}$ to $8900 \mathrm{~cm}^{2} / \mathrm{g}$. The curing temperature is $20^{\circ} \mathrm{C}$. The used cement is moderate heat Portland cement. By using Portland cement hydration model shown in Section 2.1, the hydration rate of control cement paste without limestone is calculated and shown in Figure 1(a). The $y$-axis of Figure 1(a) represents the heat release for cement portions in cement-limestone blends.

Furthermore, based on experimental results about hydration heat of limestone blended cement paste, the enhanced coefficients $A_{1}$ and $A_{2}$ (shown in (8) and (9)) are set as 0.6. As shown from Figures $1(\mathrm{~b})-1(\mathrm{~d})$, the analysis results generally agree with experimental results. Figure 1(e) shows calculation results of rate of hydration heat. When cement is partially replaced by limestone, the value of the second peak of hydration heat increases, and the time corresponding to the second peak becomes much earlier. This trend agrees with experimental results about the rate of heat evolution of limestone blended cement paste [11]. When the surface area of Blaine surface of limestone increases, the nucleation effect becomes more significant, and the value of the second peak of hydration heat also increases. Hence limestone with a high Blaine surface is more effective in improving the hydration of cement.

3.2. Parameter Analysis about Hydration Heat. Parameter studies are carried out to analyze the degree of hydration and hydration heat of hardening concrete with different limestone replacement ratios and water to binder ratios. The water to binder ratio ranges from 0.3 to 0.5 , and limestone content ranges from $15 \%$ to $30 \%$. The curing temperature is assumed as $20^{\circ} \mathrm{C}$.

The calculated degree of hydration is shown in Figure 2. Due to dilution effect and nucleation effect, the degree of hydration in cement-limestone blends is higher than that in control concrete. Moreover, for concrete with a lower water to binder ratio 0.3 , when cement is partially replaced by limestone, the change of water to cement ratio is significant; hence the improvement of the degree of hydration is also obvious.

The relative degree of hydration means the ratio of the degree of hydration of limestone blended concrete to that of control concrete. Figure 3 shows relative degree of hydration. Given a certain limestone content, concrete with a lower water to binder ratio has a higher relative degree of hydration. This agrees with Bonavetti et al. [19] and Bentz et al.s [20] study. They stated that limestone filler used in low water to cement ratio concrete is a rational option for saving energy.

As shown in (10), hydration heat relates to both cement content and degree of hydration. For limestone blended concrete, the degree of hydration increases which increases hydration heat, while the cement content decreases due to limestone replacing partial cement which reduces hydration heat. The total hydration heat depends on the combined 


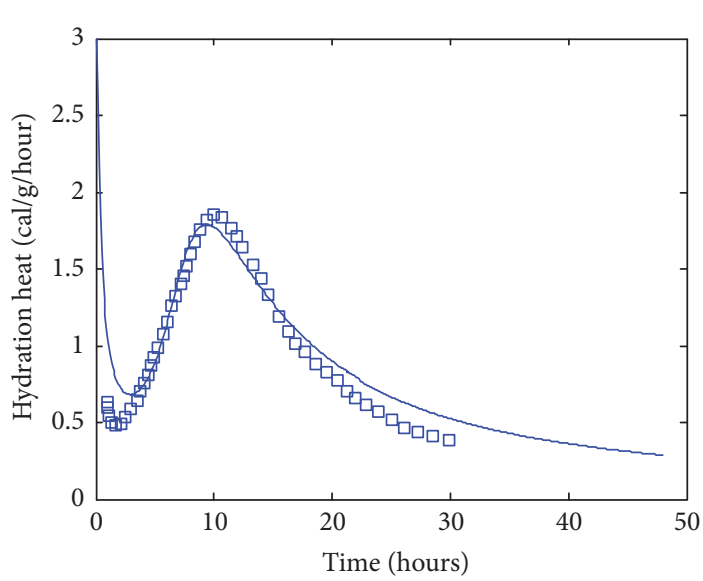

- Analysis results

$\square$ Experimental results

(a) $100 \%$ Portland cement

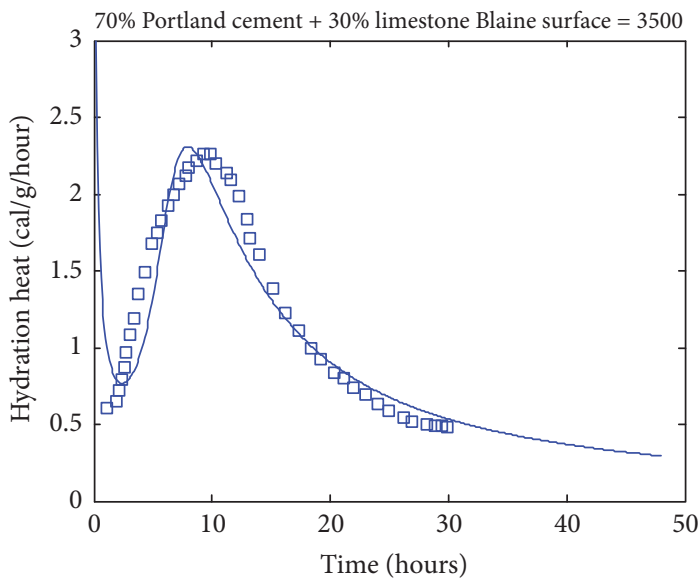

- Analysis results

口 Experimental results

(c) $70 \%$ Portland cement $+30 \%$ limestone

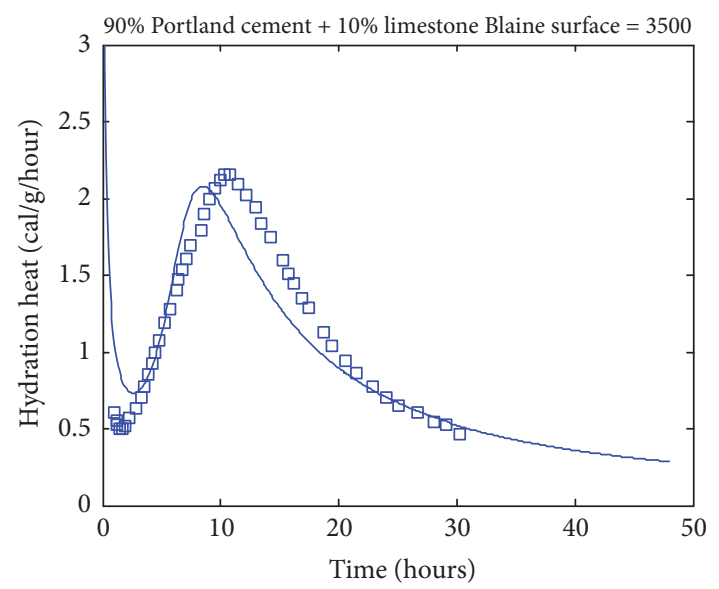

Analysis results

$\square \quad$ Experimental results

(b) $90 \%$ Portland cement $+10 \%$ limestone

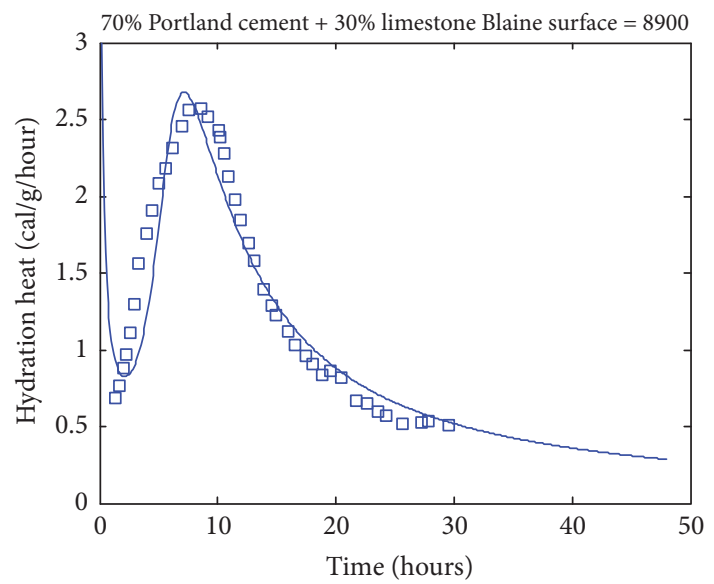

- Analysis results

$\square \quad$ Experimental results

(d) $70 \%$ Portland cement $+30 \%$ limestone with high Blaine surface

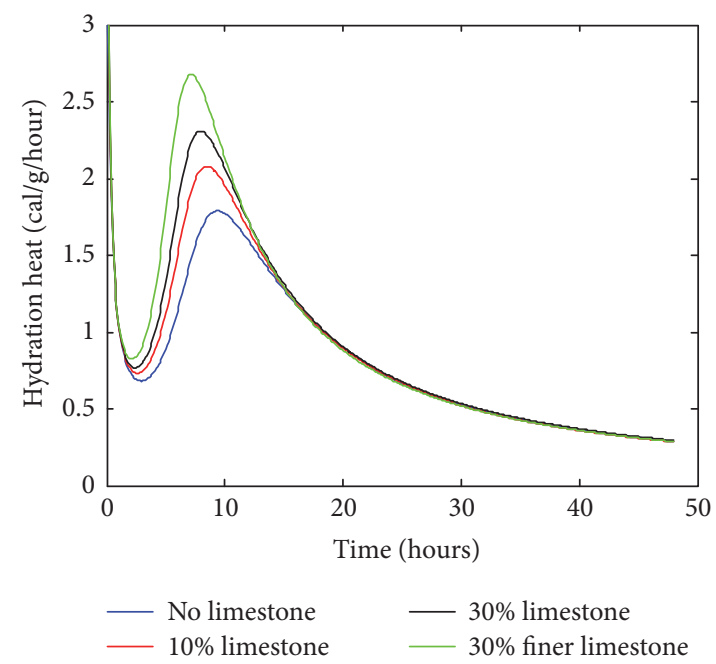

(e) Effect of limestone powder on the rate of hydration heat

FIGURE 1: Rate of hydration heat. 


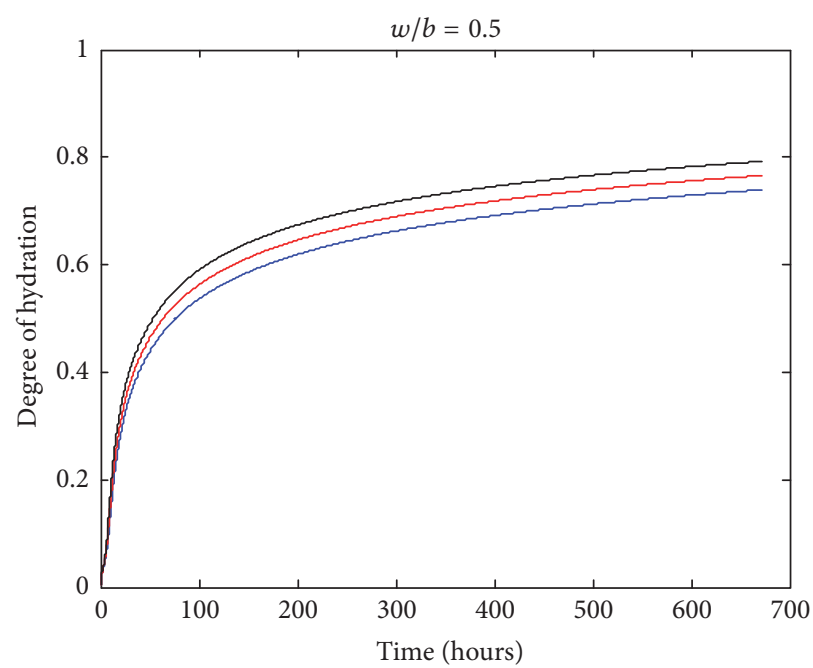

— No limestone

- $15 \%$ limestone

- $30 \%$ limestone

(a) Water to binder ratio 0.5

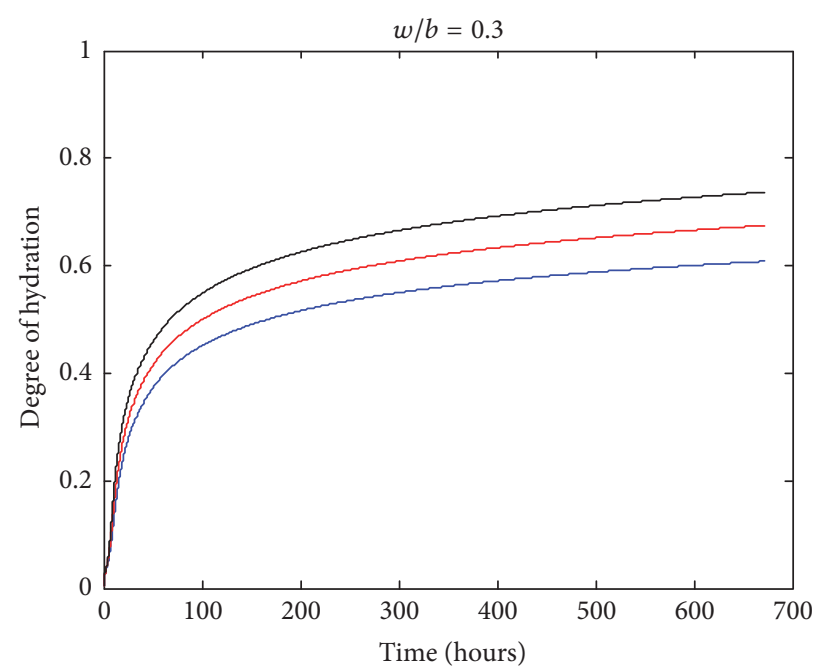

- No limestone

- 15\% limestone

- $30 \%$ limestone

(b) Water to binder ratio 0.3

Figure 2: Degree of hydration.

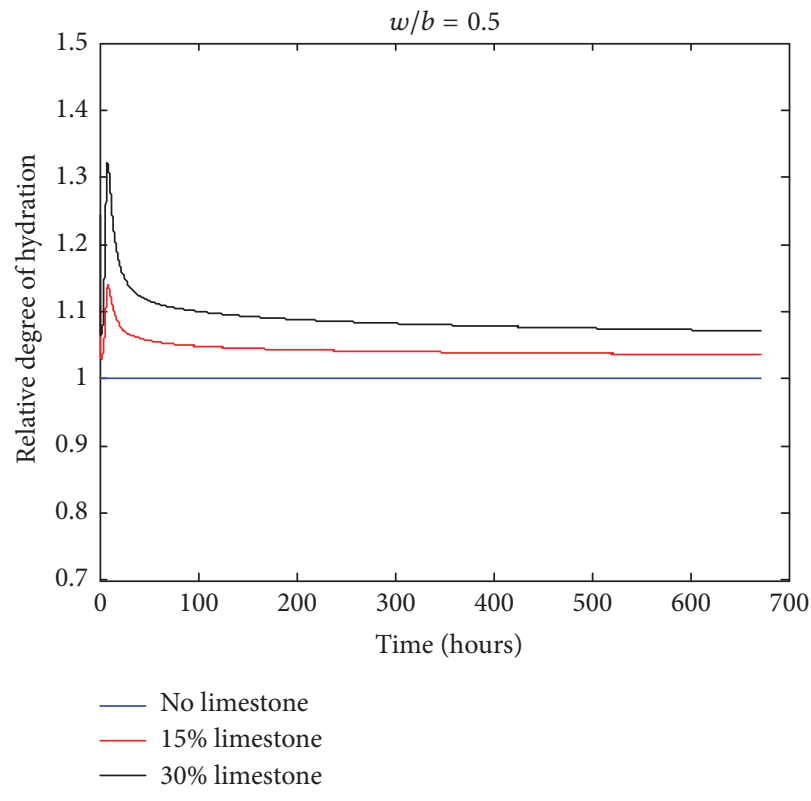

(a) Water to binder ratio 0.5

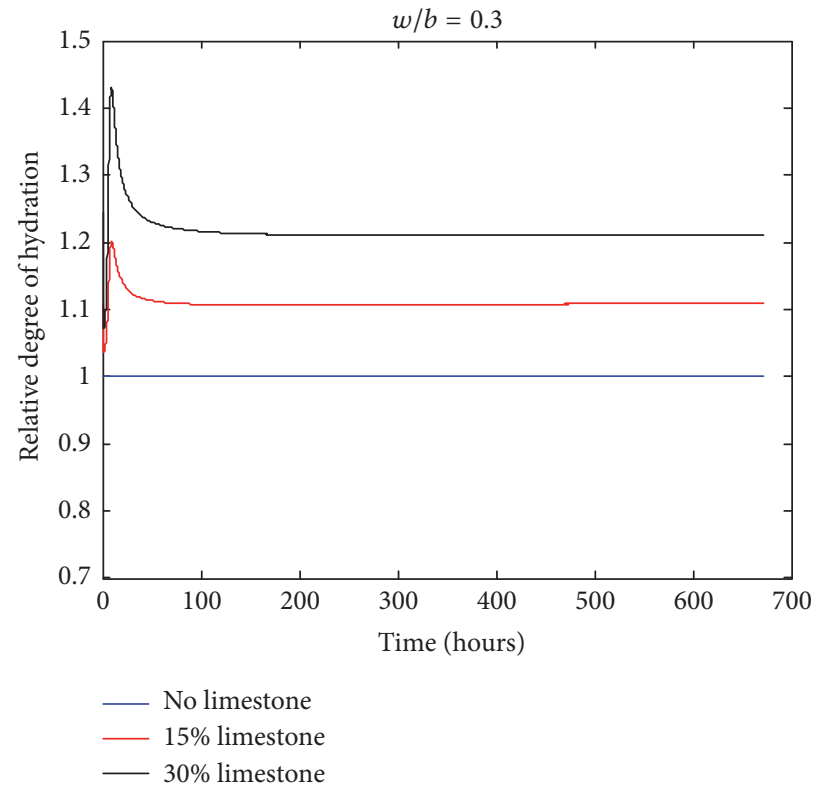

(b) Water to binder ratio 0.3

FIGURE 3: Relative degree of hydration.

action of increasing factor and decreasing factor, that is, degree of hydration and cement content. The relative heat of hydration means the ratio of heat of hydration of limestone blended concrete to that of control concrete. Figure 4 shows relative heat of hydration. Limestone blended concrete has a lower hydration heat than control concrete. Given a certain limestone content, concrete with a lower water to binder ratio has a higher relative heat of hydration. This agrees with Chen and Kwan's study [5]. Limestone addition can reduce the hydration heat of concrete and decrease the tendency of thermal cracking of hardening concrete.

3.3. Temperature History of Semiadiabatic Temperature Rise. Experimental results about semiadiabatic temperature rise shown in [14] are used to verify the proposed semiadiabatic temperature rise model. Table 2 shows the mixing proportions of concrete. The initial temperature and ambient temperature for each specimen are also shown in Table 2. 

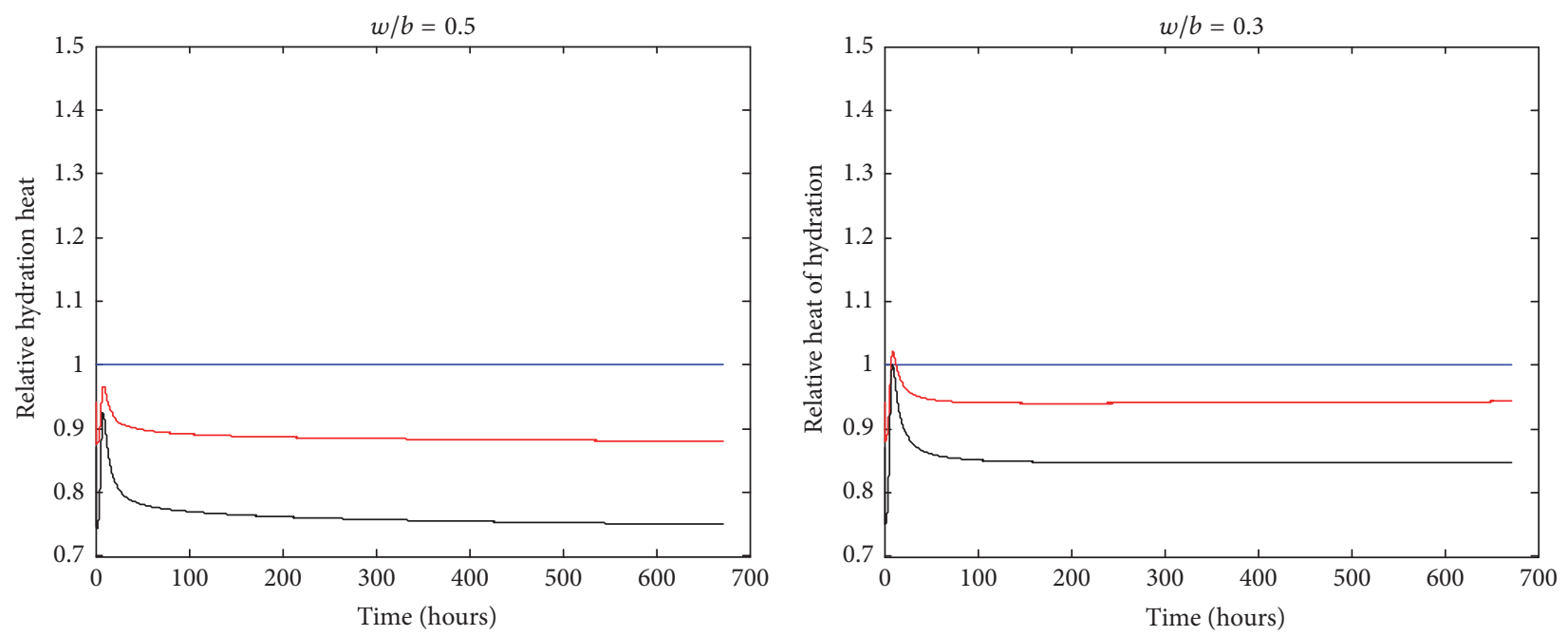

— No limestone

_ $15 \%$ limestone

— No limestone

_ $15 \%$ limestone

- $30 \%$ limestone

(a) Water to binder ratio 0.5

- $30 \%$ limestone

(b) Water to binder ratio 0.3

FIGURE 4: Relative heat of hydration.

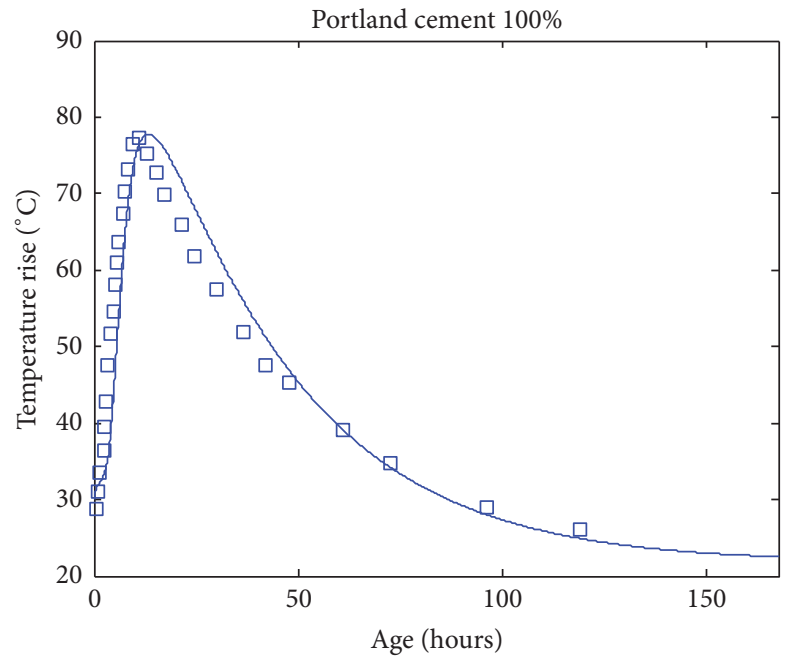

- Analysis results

$\square$ Experimental results

(a) Temperature history

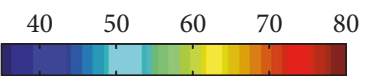

Temperature distribution at 0.5 days

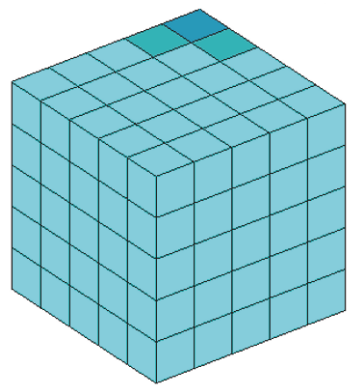

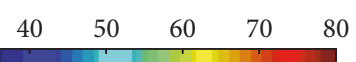

Temperature distribution at 1 day

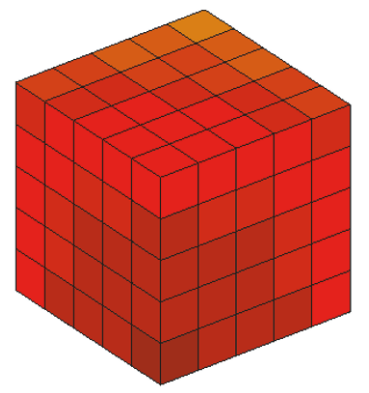

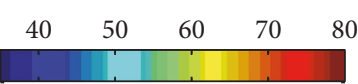

Temperature distribution at 1.5 days

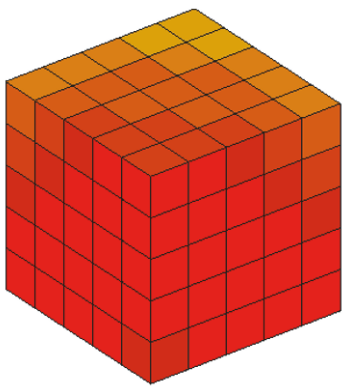

$\begin{array}{lllll}40 & 50 & 60 & 70 & 80\end{array}$

Temperature distribution at 2 days

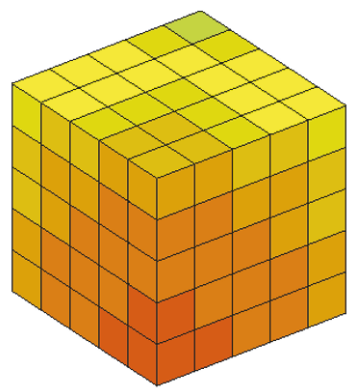

(b) Temperature distribution

FIGURE 5: OPC concrete. 


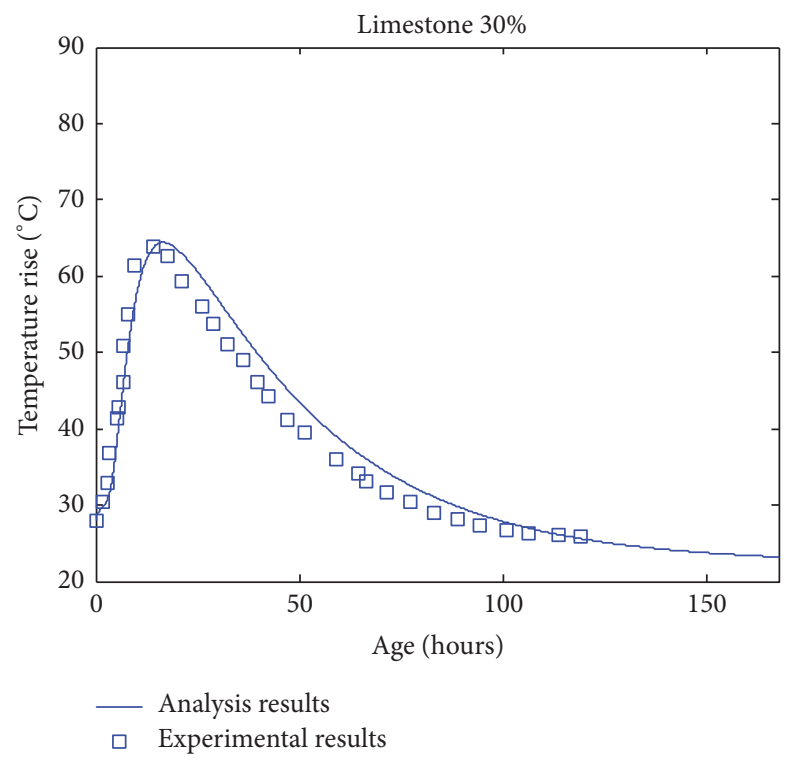

(a) Temperature history

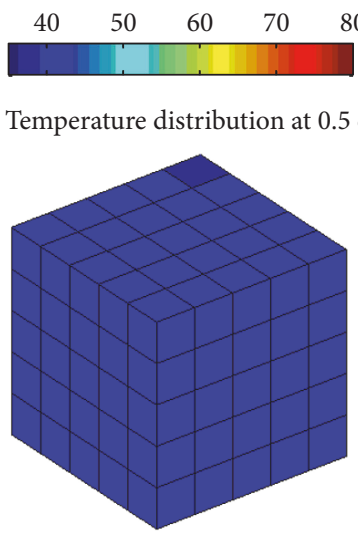

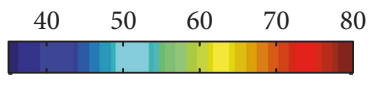

Temperature distribution at 1 day

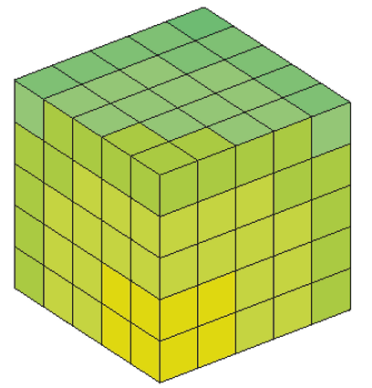

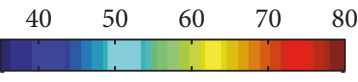

Temperature distribution at 1.5 days

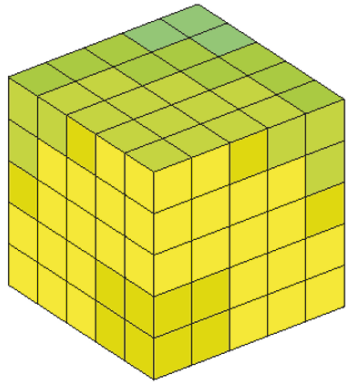

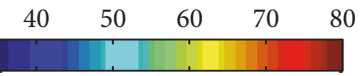

Temperature distribution at 2 days

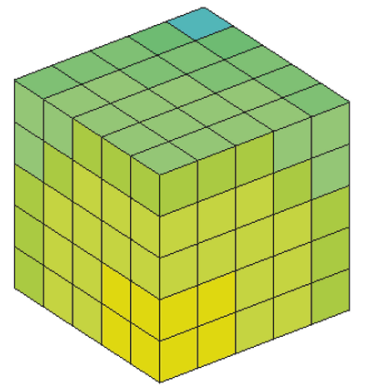

(b) Temperature distribution

FIgURE 6: Limestone 30\% concrete.

TABLE 2: Mixing proportions of concrete.

\begin{tabular}{|c|c|c|c|c|c|c|c|c|c|}
\hline & Water/(cement + limestone) & $\begin{array}{c}\text { Water } \\
\left(\mathrm{kg} / \mathrm{m}^{3}\right)\end{array}$ & $\begin{array}{l}\text { Cement } \\
\left(\mathrm{kg} / \mathrm{m}^{3}\right)\end{array}$ & $\begin{array}{c}\text { Limestone } \\
\left(\mathrm{kg} / \mathrm{m}^{3}\right)\end{array}$ & $\begin{array}{c}\text { Sand } \\
\left(\mathrm{kg} / \mathrm{m}^{3}\right)\end{array}$ & $\begin{array}{c}\text { Gravel } \\
\left(\mathrm{kg} / \mathrm{m}^{3}\right)\end{array}$ & $\begin{array}{c}\text { Superplasticizer } \\
\left(\mathrm{kg} / \mathrm{m}^{3}\right)\end{array}$ & $\begin{array}{c}\text { Initial } \\
\text { temperature } \\
\left({ }^{\circ} \mathrm{C}\right)\end{array}$ & $\begin{array}{c}\text { Ambient } \\
\text { temperature } \\
\left({ }^{\circ} \mathrm{C}\right) \\
\end{array}$ \\
\hline OPC & 30.3 & 171 & 565 & - & 820 & 915 & 1.0 & 30 & 23 \\
\hline $\begin{array}{l}\text { Limestone } \\
30 \%\end{array}$ & 32.7 & 177 & 396 & 146 & 820 & 915 & 0.7 & 28 & 23 \\
\hline $\begin{array}{l}\text { Limestone } \\
55 \%\end{array}$ & 32.6 & 168 & 226 & 291 & 820 & 916 & 0.7 & 28 & 23 \\
\hline $\begin{array}{l}\text { Limestone } \\
70 \%\end{array}$ & 32.0 . & 165 & 155 & 362 & 820 & 915 & 0.7 & 28 & 28 \\
\hline
\end{tabular}

The water to binder ratio is about 0.3 , and the limestone replacement ratio ranges from $30 \%$ to $70 \%$. The compound compositions of cement are shown in Table 3. The used cement is ordinary Portland cement. The size of specimens is $445 \mathrm{~mm} * 445 \mathrm{~mm} * 445 \mathrm{~mm}$. The temperature at center point is measured from mixing time to the age of five days.
Thermal conductivity and heat transfer coefficient of specimens are $41 \mathrm{kcal} / \mathrm{m} /$ day $/ \mathrm{k}$ and $35 \mathrm{kcal} / \mathrm{m}^{2} /$ day $/ \mathrm{k}$, respectively.

Because of symmetries of geometry condition and boundary condition of the specimen, a one-eighth specimen is adopted to represent the full specimen. The 8-node brick isoparametric element is used to mesh the specimen in 


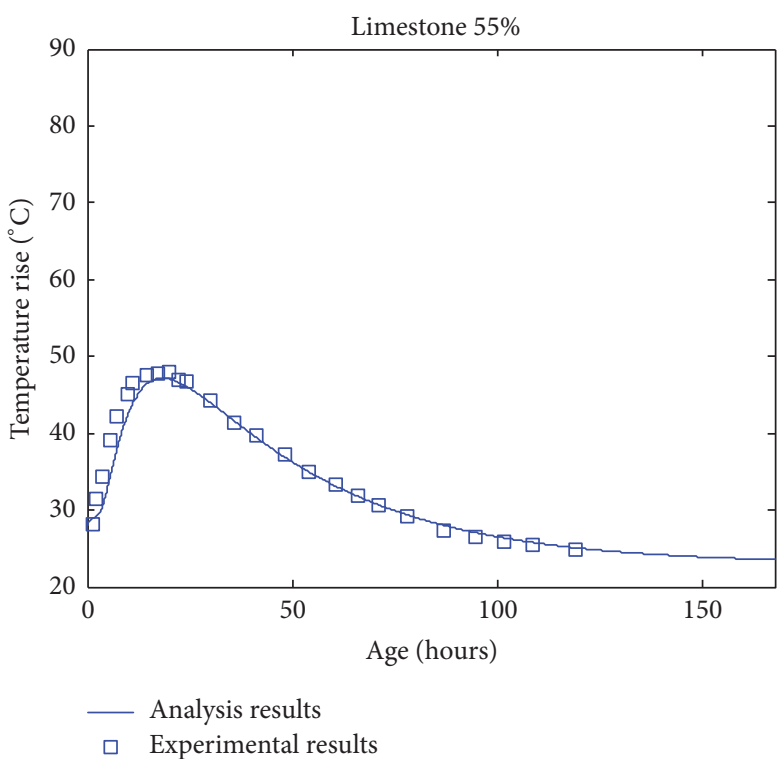

(a) Temperature history
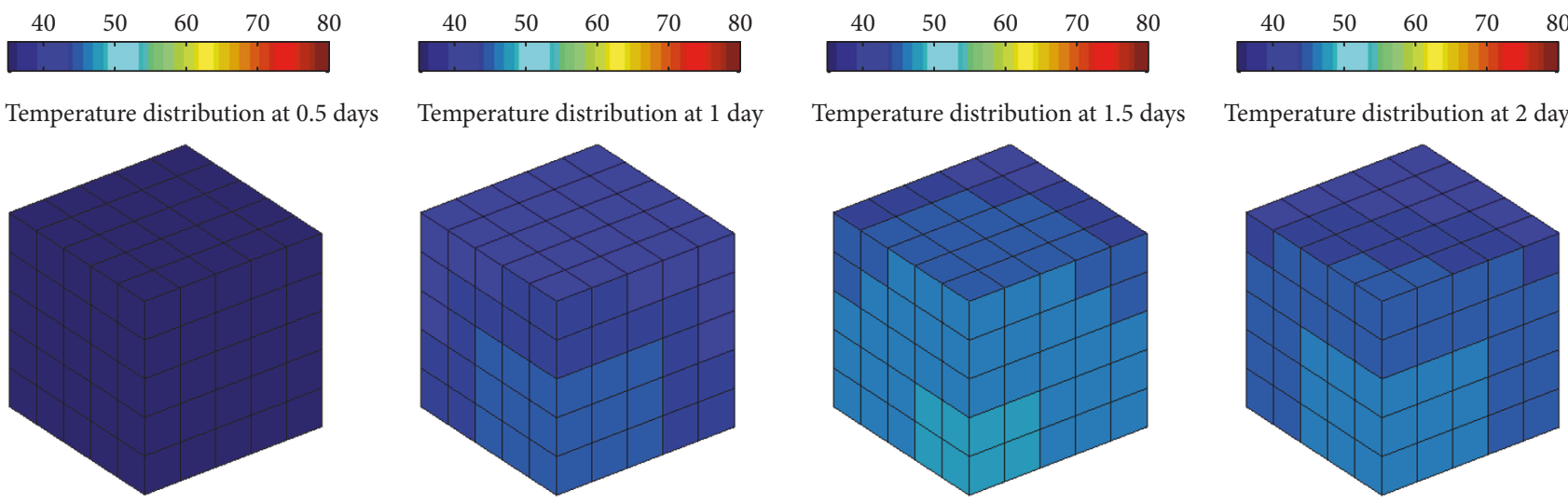

(b) Temperature distribution

FIGURE 7: Limestone 55\% concrete.

TABLE 3: Compound compositions of cement.

\begin{tabular}{ccccccc}
\hline & $\begin{array}{c}\mathrm{C}_{3} \mathrm{~S} \\
\%\end{array}$ & $\begin{array}{c}\mathrm{C}_{2} \mathrm{~S} \\
\%\end{array}$ & $\begin{array}{c}\mathrm{C}_{3} \mathrm{~A} \\
\%\end{array}$ & $\begin{array}{c}\mathrm{C}_{4} \mathrm{AF} \\
\%\end{array}$ & $\begin{array}{c}\text { Gypsum } \\
\%\end{array}$ & $\begin{array}{c}\text { Blaine } \\
\left(\mathrm{cm}^{2} / \mathrm{g}\right)\end{array}$ \\
\hline Cement & 53.9 & 18.8 & 11.0 & 10.4 & 5.83 & 3350 \\
\hline
\end{tabular}

three-dimensional spaces. Total 125 elements $(5 * 5 * 5=$ 125) are used. In each time step, the heat evolution rate of each element is determined from current temperature of the element. Figures 5-8 show the calculation results about temperature history and temperature distribution of hardening concrete. With the increasing of limestone content, the maximum temperature rise of concrete decreases. For control concrete, $30 \%$ limestone concrete, and 50\% limestone concrete, the calculation results about temperature history generally agree with experimental results, while, for $70 \%$ limestone blended concrete, at early ages, the calculation result is slightly lower than experimental results. This may be due to heat release from the chemical reaction of limestone.
For concrete with very high content limestone, the chemical reaction of limestone becomes significant and can contribute to the temperature rise of hydrating concrete. The proposed model considers the acceleration of cement hydration due to temperature increasing. However, the reduction of solubility of concrete due to temperature increasing is not considered. The point should be taken into account in the future study.

\section{Conclusions}

This study proposes a numerical procedure for predicting temperature history of hardening limestone blended concrete. The numerical procedure combines a kinetic limestone blended cement hydration model with a finite element method.

First, the hydration model analyzes the dilution effect and nucleation effect due to limestone additions. For concrete with a lower water to binder ratio, the dilution effect due to limestone addition becomes obvious, and the degree of 


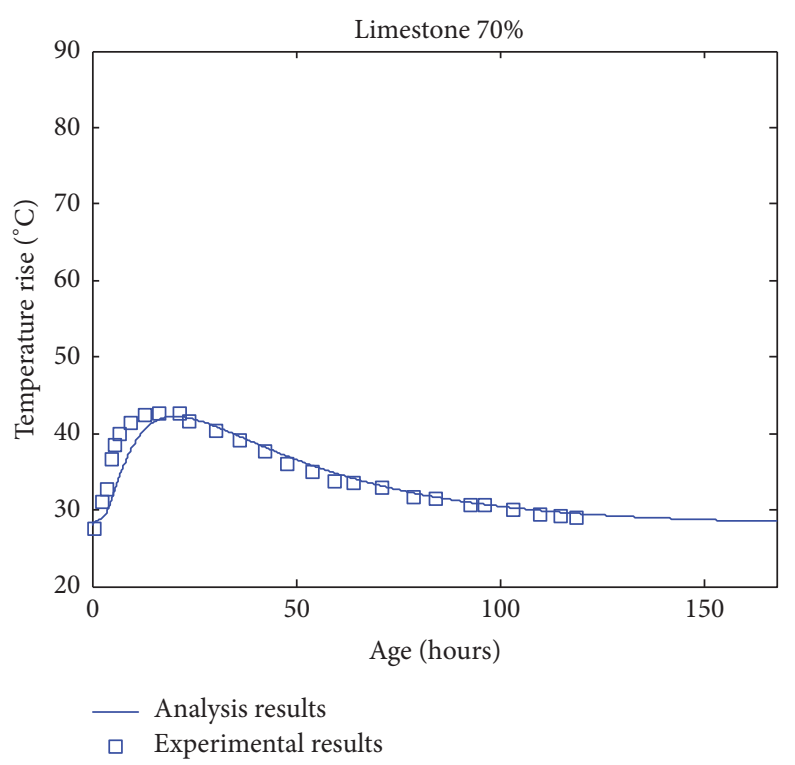

(a) Temperature history
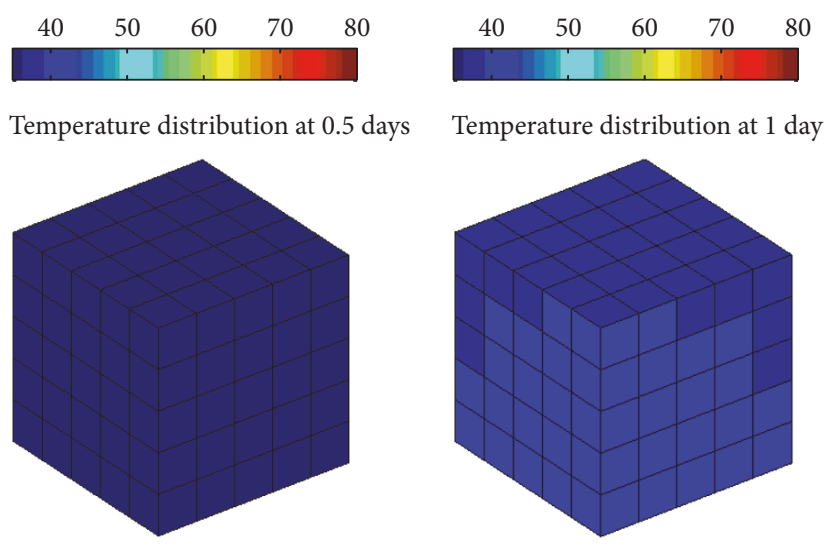

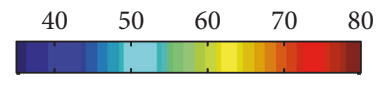

Temperature distribution at 1.5 days

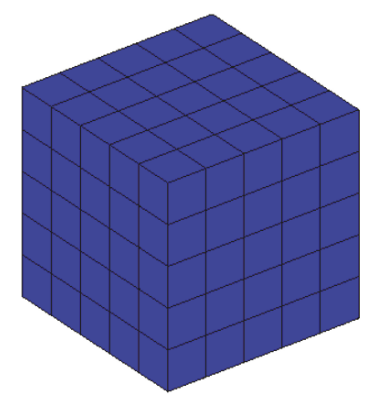

Temperature distribution at 2 days

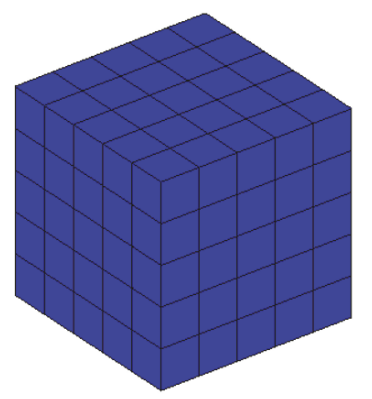

(b) Temperature distribution

FIGURE 8: Limestone 70\% concrete.

hydration is significantly improved compared with control concrete without limestone.

Second, the released heat of concrete relates to both cement content and degree of hydration. Limestone additions increase the degree of hydration but reduce cement content. The total hydration heat depends on the combined action of cement content and degree of hydration. The results of parameter analysis show that limestone additions can reduce the heat of hydration.

Third, the calculation results of hydration heat from hydration model are used as input parameters of finite element model. The combined hydration and finite element model can be used to evaluate temperature history and temperature distribution of semiadiabatic hardening concrete. The analysis results show that, with the increasing of limestone content, the maximum temperature rise of concrete decreases.

\section{Conflicts of Interest}

The author declares that they have no conflicts of interest.

\section{Acknowledgments}

This research was supported by a grant from Smart Civil Infrastructure Research Program (13SCIPA02) funded by Ministry of Land, Infrastructure and Transport (MOLIT) of Korean Government and Korea Agency for Infrastructure Technology Advancement (KAIA).

\section{References}

[1] S. H. Liu and P. Y. Yan, "Effect of limestone powder on microstructure of concrete," Journal Wuhan University of Technology, Materials Science Edition, vol. 25, no. 2, pp. 328-331, 2010. 
[2] V. Bonavetti, H. Donza, V. Rahhal, and E. Irassar, "Influence of initial curing on the properties of concrete containing limestone blended cement," Cement and Concrete Research, vol. 30, no. 5, pp. 703-708, 2000.

[3] I. Mohammadi and W. South, "Decision-making on increasing limestone content of general purpose cement," Journal of Advanced Concrete Technology, vol. 13, no. 11, pp. 528-537, 2015.

[4] J. Mohammadi and W. South, "Effects of intergrinding $12 \%$ limestone with cement on properties of cement and mortar," Journal of Advanced Concrete Technology, vol. 14, no. 5, pp. 215228, 2016.

[5] J. J. Chen and A. K. H. Kwan, "Adding limestone fines to reduce heat generation of curing concrete," Magazine of Concrete Research, vol. 64, no. 12, pp. 1101-1111, 2012.

[6] S. Palm, T. Proske, M. Rezvani, S. Hainer, C. Müller, and C.-A. Graubner, "Cements with a high limestone content - Mechanical properties, durability and ecological characteristics of the concrete," Construction and Building Materials, vol. 119, pp. 308-318, 2016.

[7] B. Lothenbach, G. Le Saout, E. Gallucci, and K. Scrivener, "Influence of limestone on the hydration of Portland cements," Cement and Concrete Research, vol. 38, no. 6, pp. 848-860, 2008.

[8] D. P. Bentz, "Modeling the influence of limestone filler on cement hydration using CEMHYD3D," Cement and Concrete Composites, vol. 28, no. 2, pp. 124-129, 2006.

[9] A. R. Mohamed, M. Elsalamawy, and M. Ragab, "Modeling the influence of limestone addition on cement hydration," Alexandria Engineering Journal, vol. 54, no. 1, pp. 1-5, 2015.

[10] A.-M. Poppe and G. De Schutter, "Analytical hydration model for filler rich binders in self-compacting concrete," Journal of Advanced Concrete Technology, vol. 4, no. 2, pp. 259-266, 2006.

[11] G. Ye, X. Liu, A. M. Poppe, G. De Schutter, and K. Van Breugel, "Numerical simulation of the hydration process and the development of microstructure of self-compacting cement paste containing limestone as filler," Materials and Structures/Materiaux et Constructions, vol. 40, no. 9, pp. 865-875, 2007.

[12] X. Wang and H. Lee, "Modeling the hydration of concrete incorporating fly ash or slag," Cement and Concrete Research, vol. 40, no. 7, pp. 984-996, 2010.

[13] X.-Y. Wang, "Modeling of hydration, compressive strength, and carbonation of portland-limestone cement (PLC) concrete," Materials, vol. 10, no. 2, article 115, 2017.

[14] T. Kishi and D. Saruul, "Hydration heat modeling for cement with limestone powder," Iabse Colloquium Phuket, vol. 81, pp. 133-138, 1999.

[15] J. D. Logan, A First Course in Differential Equations, Undergraduate Texts in Mathematics, Springer, New York, 5th edition, 2011.

[16] B. F. Zhu, Thermal Stresses and Temperature Control of Mass Concrete, Tsinghua University Press, Beijing, China, 2014.

[17] K. Maekawa, T. Ishida, and T. Kishi, Multi-Scale Modeling of Structural Concrete, Taylor \& Francis, New York, NY, USA, 2009.

[18] W. Xiao-Yong, "Prediction of temperature distribution in hardening silica fume-blended concrete," Computers and Concrete, vol. 13, no. 1, pp. 97-115, 2014.

[19] V. Bonavetti, H. Donza, G. Menéndez, O. Cabrera, and E. F. Irassar, "Limestone filler cement in low w/c concrete: A rational use of energy," Cement and Concrete Research, vol. 33, no. 6, pp. 865-871, 2003.
[20] D. P. Bentz, E. F. Irassar, B. E. Bucher, and W. J. Weiss, "Limestone fillers conserve cement, part 2: durability issues and the effects of limestone fineness on mixtures," Concrete International, vol. 31, pp. 35-40, 2009. 

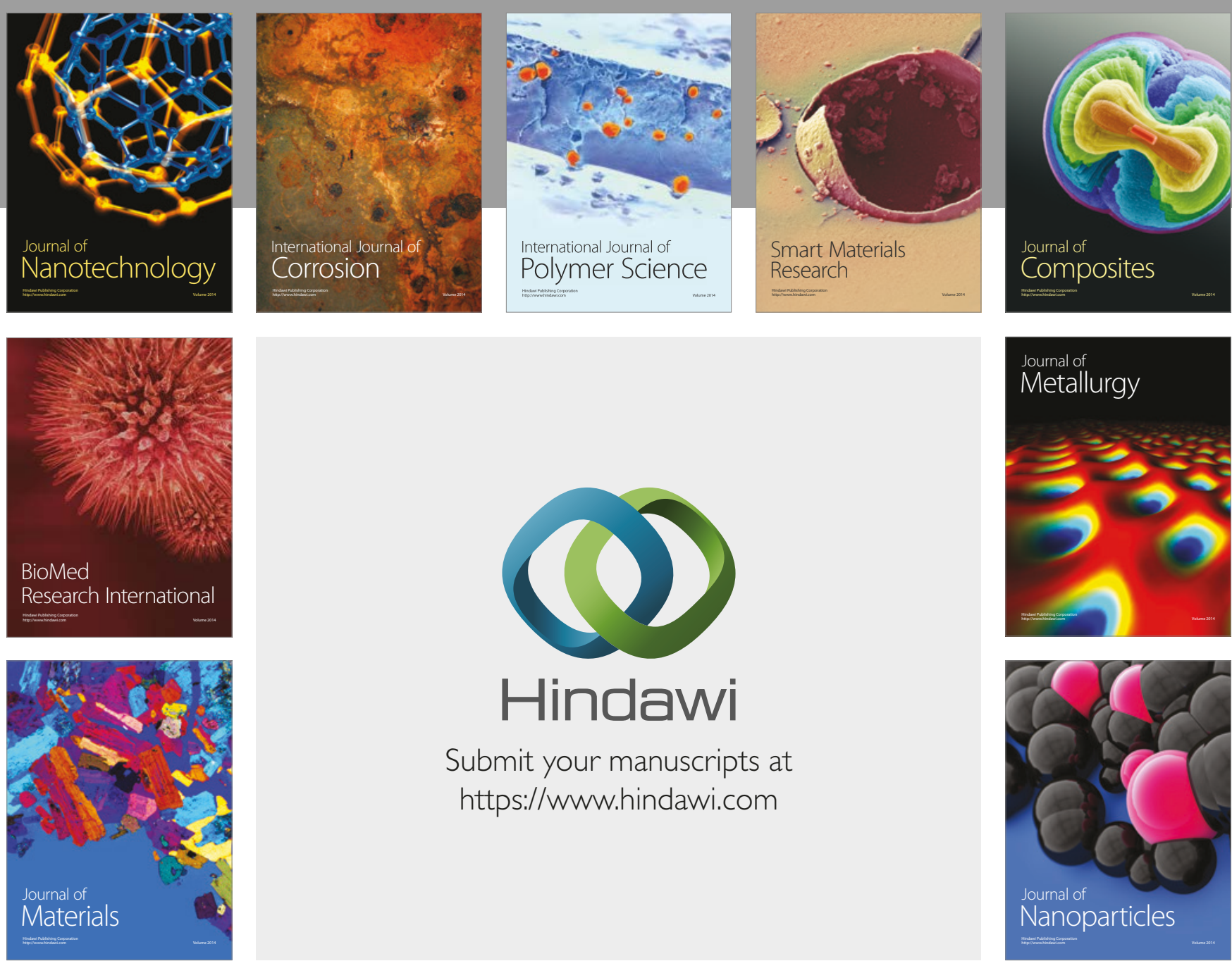

\section{Hindawi}

Submit your manuscripts at

https://www.hindawi.com
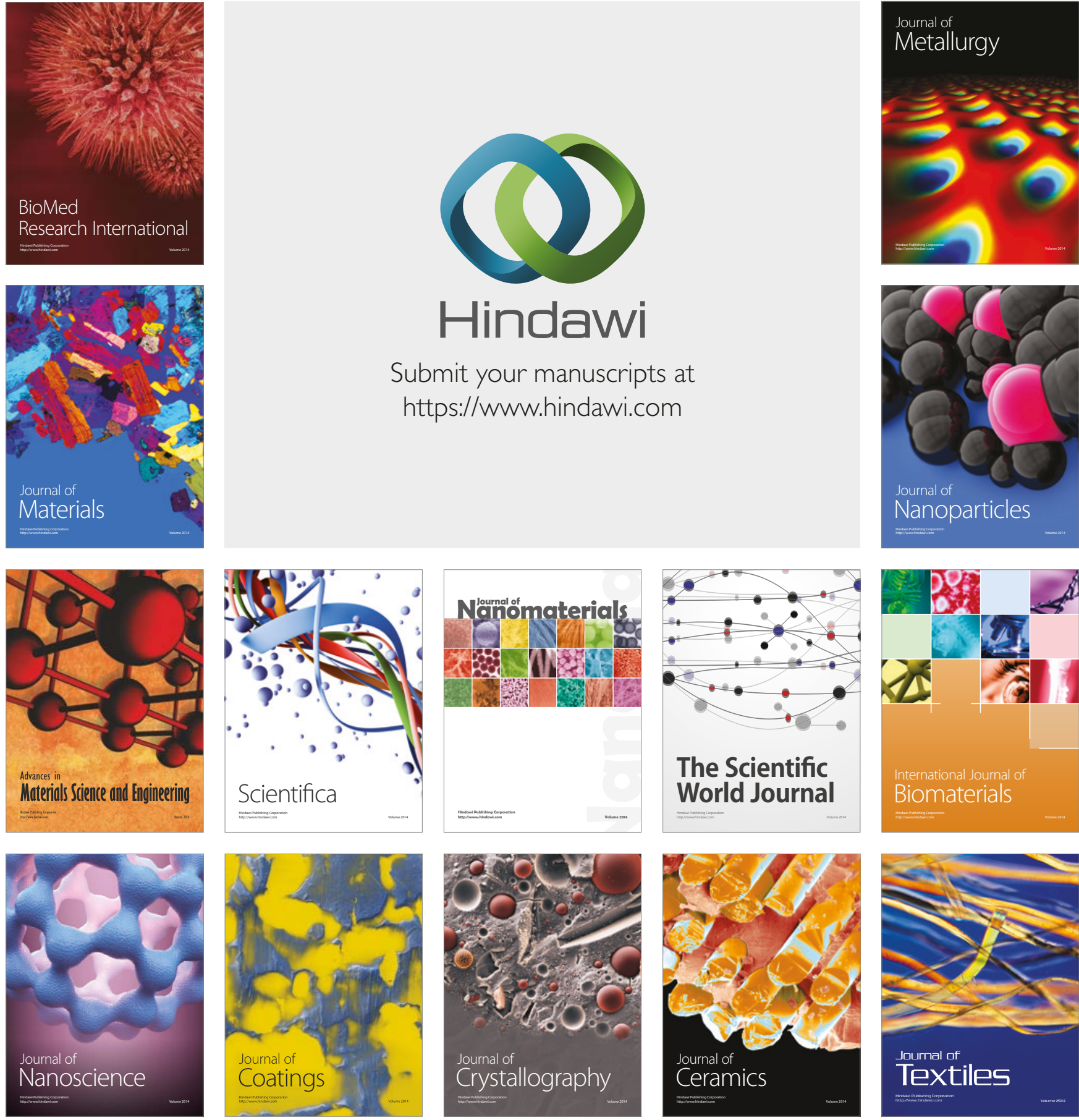

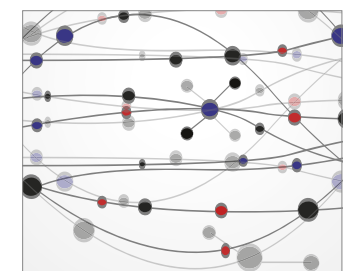

The Scientific World Journal
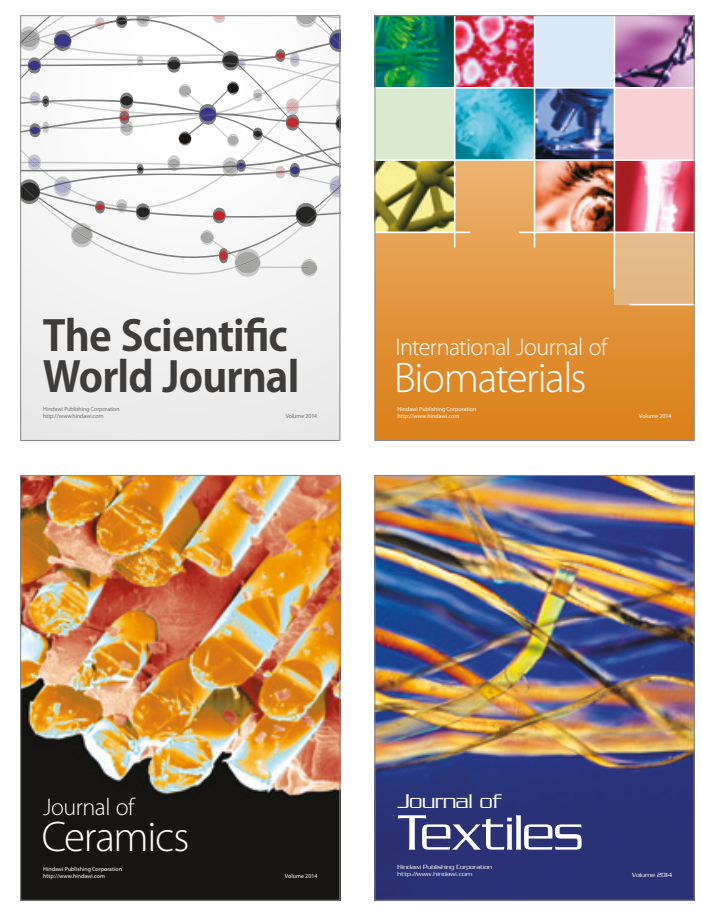